\title{
Аналіз можливих способів підвищення точності реактивних снарядів середнього калібру шляхом комплектування їх системою керування
}

\author{
Андрій Вакал ${ }^{1}$ А; Олег Степаненко 2 в; Микола Дорофєєв 3 C \\ А Сумський державний університет, вул. Римського-Корсакова, 2, м. Суми, 40000, Україна \\ ${ }^{в}$ Науково-дослідний центр ракетних військ і артилерії, вул. Герасима Кондратьєва, 165, м. Суми, 40021, Україна \\ с Центральний науково-дослідний інститут озброєння та військової техніки 3С України, пр-кт Повітрофлотський 28, м. Київ, 03049, Україна
}

Received: December 25, 2020 | Revised: February 13, 2021 | Accepted: February 28, 2021

DOI: $10.33445 /$ sds.2021.11.1.2

\begin{abstract}
Анотація
У статті проведено аналіз відомих конструктивних рішень, що використовуються для комплектування некерованих авіаційних ракет та некерованих реактивних снарядів системами керування з метою підвищення їх точності. Розглядаються можливі способи комплектування реактивних боєприпасів до реактивних систем залпового вогню середнього калібру системою керування та пропонується конструктивне рішення щодо їі удосконалення.
\end{abstract}

Ключові слова: високоточні боєприпаси, реактивна система залпового вогню, система керування, автономний блок керування, волоконний оптичний гіроскоп.

\section{Постановка проблеми}

Продовження ескалації збройного конфлікту на сході України вимагає від керівництва нашої Держави і Збройних Сил України постійно визначати подальші пріоритетні напрямки підвищення боєздатності військових частин (підрозділів) Збройних Сил України. Реактивні системи залпового вогню (РСЗВ) середнього калібру неодноразово доводили свою ефективність під час ведення бойових дій у різних збройних конфліктах по всьому світу і продовжують залишатись одним із основних вогневих засобів, що застосовується у зоні проведення ООС. В умовах гібридної війни підрозділи, озброєні РСЗВ середнього калібру, при ураженні цілей, розташованих в населених пунктах, не можуть компенсувати недостатню точність стрільби збільшенням кількості витрачених боєприпасів. Ефективного виконання вогневих завдань у зазначених умовах можна досягти за рахунок суттєвого підвищення точності боєприпасів до РСЗВ середнього калібру.

\section{Аналіз останніх досліджень та публікацій}

Аналіз позитивного досвіду провідних у військовому відношенні країн світу у створенні високоточних боєприпасів (ВТБ) може бути використаний під час подальшого розроблення ВТБ для РСЗВ середнього калібру. Застосування ВТБ спільно 3 модернізованими РСЗВ середнього калібру забезпечить мінімальний час підготовки до ведення вогню та істотно скоротить час їх перебування на вогневій позиції, а значить підвищить їх живучість і зробить контрбатарейну боротьбу противника менш ефективною $[1,7]$.

\footnotetext{
${ }^{1}$ Corresponding author: к.т.н., с.н.с., доцент кафедри, e-mail: vakal240870@gmail.com, ORCID: 0000-0001-7568-7686

${ }^{2}$ Старший науковий співробітник науково-дослідного відділу, e-mail: vip.oleg200673@ukr.net, ORCID: 0000-0002-8044-2292

${ }^{3}$ Науковий співробітник науково-дослідного відділу, e-mail: dorofeev83@meta.ua, ORCID: 0000-0001-8607-2483
} 


\section{Постановка завдання}

Метою статті $€$ аналіз досвіду провідних у військовому відношенні країн світу у створенні ВТБ для авіаційних пускових установок (АПУ) та РСЗВ середнього калібру шляхом комплектування некерованих боєприпасів системами керування, визначення преваг і недоліків використаних конструктивних рішень та можливих напрямків їх удосконалення.

\section{Виклад основного матеріалу}

Одним із способів створення ВТБ у некерованих реактивних снарядів (НРС) багатьох розвинених у військовому системами керування різного типу. Деякі відношенні країнах світу $\epsilon$ обладнання основні параметри цих боєприпасів наведено некерованих авіаційних ракет (НАР) та в табл. 1.

Таблиця 1. - Тактико-технічні характеристики високоточних боєприпасів

\begin{tabular}{|c|c|c|c|c|c|}
\hline Назва ВТБ & $\begin{array}{l}\text { KAP “Laser } \\
\text { Guided Zuni } \\
\text { Rocket" }\end{array}$ & $\begin{array}{c}\text { КРС до РСЗВ } \\
\text { WS-22 }\end{array}$ & $\begin{array}{c}\text { KPC BRE7 } \\
\text { "Fire } \\
\text { Dragon 40" } \\
\text { до PC3B SR5 } \\
\end{array}$ & $\begin{array}{c}\text { КРС С-13Кор } \\
\text { до ПУ Б-13Л, } \\
\text { Б-13Р }\end{array}$ & $\begin{array}{l}\text { КРС до РСЗВ БМ- } \\
\text { 21, “Торнадо-Г” }\end{array}$ \\
\hline $\begin{array}{c}\text { Назва базової } \\
\text { НАР, НРС }\end{array}$ & $\begin{array}{l}\text { 127-MM HAP } \\
\text { Mk } 71 \text { Zuni }\end{array}$ & $\begin{array}{c}\text { 122-мм HPC } \\
\text { до WS-15 }\end{array}$ & $\begin{array}{c}\text { 122-мм HPC } \\
\text { до SR5 }\end{array}$ & $\begin{array}{l}\text { 122-мм НРС } \\
\text { С-13 до ПУ } \\
\text { Б-13Л, Б-13Р }\end{array}$ & $\begin{array}{c}\text { 122-мм НРC } \\
\text { М210Ф, 9M538, } \\
\text { 9M521 } \\
\text { до БМ-21 }\end{array}$ \\
\hline $\begin{array}{c}\text { Країна } \\
\text { розробник }\end{array}$ & США & Китай & Китай & РФ & $P \Phi$ \\
\hline $\begin{array}{c}\text { Система } \\
\text { керування }\end{array}$ & $\begin{array}{l}\text { WGU-58/B, } \\
\text { система } \\
\text { керуючих } \\
\text { лопастей }\end{array}$ & $\begin{array}{l}\text { Імпульсна } \\
\text { система } \\
\text { корекції } \\
\text { траєкторії }\end{array}$ & $\begin{array}{l}\text { Система } \\
\text { керуючих } \\
\text { лопастей }\end{array}$ & $\mid \begin{array}{c}\text { Імпульсна } \\
\text { система корекції } \\
\text { траєкторії }\end{array}$ & $\begin{array}{c}\text { Автономний } \\
\text { блок керування } \\
\text { “ОУ-122" }\end{array}$ \\
\hline $\begin{array}{c}\text { Система } \\
\text { наведення }\end{array}$ & $\begin{array}{c}\text { Лазерна } \\
\text { напівактивна }\end{array}$ & $\begin{array}{c}\text { Комбінована } \\
\text { INS/GPS та } \\
\text { лазерна } \\
\text { напівактивна }\end{array}$ & $\begin{array}{l}\text { Комбінована } \\
\text { INS/GPS та } \\
\text { лазерна } \\
\text { напівактивна }\end{array}$ & $\begin{array}{c}\text { Лазерна } \\
\text { напівактивна }\end{array}$ & $\begin{array}{l}\text { Кореляційна } \\
\text { INS/GPS }\end{array}$ \\
\hline $\begin{array}{c}\text { Імовірне } \\
\text { кругове } \\
\text { відхилення, м }\end{array}$ & $1,5-2$ & до 100 & $\begin{array}{c}25 \\
3(3 \Gamma \mathrm{CH})\end{array}$ & $0,8-1,8$ & 10 \\
\hline Вага без БЧ, кг & 36,1 & 52 & 56 & 62 & $\begin{array}{c}66,6 \\
69 \\
\end{array}$ \\
\hline $\begin{array}{c}\text { Стартова вага, } \\
\text { кг } \\
\end{array}$ & 68 & 73 & 74 & 70 & $\begin{array}{l}79 \\
81 \\
\end{array}$ \\
\hline $\begin{array}{c}\text { Довжина без } \\
\text { блоку } \\
\text { керування, мм }\end{array}$ & 2000 & - & - & - & $\begin{array}{l}2870 \\
2588 \\
2840 \\
\end{array}$ \\
\hline $\begin{array}{c}\text { Довжина з } \\
\text { блоком } \\
\text { керування, мм }\end{array}$ & 2800 & 3030 & 3040 & 3000 & $\begin{array}{l}3010 \\
2630 \\
2880 \\
\end{array}$ \\
\hline Діаметр, мм & 127 & 122 & 122 & 122 & 122 \\
\hline Дальність, км & до 8 & $20-45$ & $20-40$ & $2,5-9$ & $30-40$ \\
\hline
\end{tabular}

Принцип дії та будова НАР для АПУ та НРС для РСЗВ мало чим відрізняються, що створює великі можливості для їх уніфікації, а конструктивні рішення, які використовуються 
для модернізації одного виду боєприпасів (БП), можуть бути використані і для іншого. Існуючі системи керування (СК) дозволяють цілеспрямовано і в широкому діапазоні впливати на траєкторію польоту ракети або РС, тим самим виключати помилки прицілювання, наслідки коливального впливу атмосфери, початкових умов пуску та інших факторів, що відхиляють боєприпаси від цілі. В результаті точність стрільби боєприпасами, оснащеними системою керування, може бити істотно підвищена, а також збільшена дальність стрільби за рахунок їх баражування на пасивній ділянці траєкторії (ПДТ) і, як наслідок, суттєво збільшена ефективність вирішення різних вогневих завдань.

Некерований $\mathrm{PC}$ - це оперений обертовий снаряд статично стійкий на балістичній траєкторії польоту. Як об'єкт керування, такий снаряд $€$ нестаціонарним об'єктом. Так, на активній ділянці траєкторії (АДТ) його нестаціонарність обумовлена широким діапазоном швидкостей польоту $(50<\mathrm{V}<1000$ $\mathrm{M} / \mathrm{c}$ ), а на ПдТ - зміною як швидкості, так і висоти польоту. Керованість такого РС зазвичай невисока через високу - до 6-13\% статичної стійкості [2]. Тому для реалізації ефективного керування таким снарядом необхідні значні керуючі моменти (сили).

Оптимальний вибір СК для боєприпасів до РСЗВ середнього калібру може бути успішно реалізований з урахуванням як особливостей самих РС, так і з урахуванням тих бойових завдань, які вирішуються з їх допомогою.

Досягнуті показники точності сучасних ВТБ підтверджують можливість розроблення їх для РСЗВ середнього калібру, що матимуть середньоквадратичне відхилення (СКВ) на рівні від 1,5 до 10 м. Такі показники точності цих боєприпасів можуть бути досягнуті за рахунок їх комплектування автономними, неавтономними або комбінованими СК. Поява відносно дешевої високоточної i компактної супутникової радіонавігаційної апаратури призвела до можливості створення СК, що забезпечують розроблення ВТБ з помилками стрільби в межах 5-7 м на всіх дистанціях стрільби $[5,6]$.
У той же час розроблення ВТБ на основі НАР або НРC потребує вирішення ряду складних завдань, пов'язаних 3 встановленням на них СК. Одним 3 таких завдань $€$ забезпечення стійкого керування польотом РС під час його обертання.

Одним з можливих варіантів вирішення цього завдання $€$ розміщення СК на РС таким чином, щоб вона мала стабілізоване положення (не оберталася) під час його обертання у польоті. Цього можна досягти за рахунок використання гіростабілізаційної платформи або спеціального відсіку, який не обертається під час польоту РС.

Гіростабілізаційна платформа використовується для розміщення СК В конструкціях ВТБ багатьох країн світу. Одним із відомих прикладів подібної модернізації серійної HAP $€$ ракета "Zuni" з лазерним наведенням (Laser Guided Zuni Rocket) (рис. 1). У головній частині цієї ракети розміщена секція $з$ CK WGU-58/B, що обладнана приймачем віддзеркаленого лазерного променю у носовій частині. Ця ракета може запускатись зі стандартного пускового контейнера з трубчатими напрямними [8].

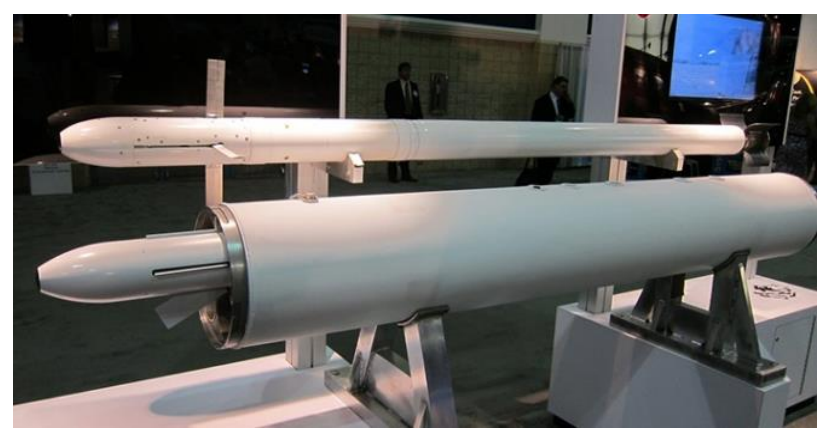

Рисунок 1 - Ракета "Zuni"

Конструктивне рішення щодо встановлення СК у відсіку РС, що не обертається, полягає у розміщенні СК 3 керуючими системами та джерелом живлення в окремому блоці, що не обертається під час польоту РС. Цей блок можна встановити перед бойовою частиною PC і з'єднати з корпусом, який обертається, за допомогою підшипникового механізму. Це конструктивне рішення використовується на авіаційних ракетах типу С25Л, С-25ЛД. Застосування такого варіанта для РС 
середнього калібру можливе лише за умови зменшення маси і габаритів блоку СК, тому що у відомих прототипів він має занадто велику масу (близько 40-50 кг) та габарити [3].

Також відомим способом, який застосовується під час розроблення ВТБ на основі існуючих НАР, $€$ варіант, в якому головна частина ракети разом з СК та бойовою частиною складає єдину конструкцію, яка не обертається. Після проходження АДТ ця головна частина відокремлюється від відсіку двигуна, який обертається. Це дозволяє виключити гіроскопічні моменти при управлінні вектором швидкості за напрямом руху головної частини, яка не обертається. Головна частина обладнується блоком СК, бойовою частиною, датчиками зовнішнього поля, керуючими пристроями та системою живлення. Після відокремлення від двигуна головна частина спрямовується на ціль за допомогою встановленої СК. Прикладом реалізації цього технічного рішення $\epsilon$ російський комплекс авіаційного керованого озброєння С-8Кор, С-13Кор (рис. 2), що створювався на основі НАР С-8, С-13 [3].

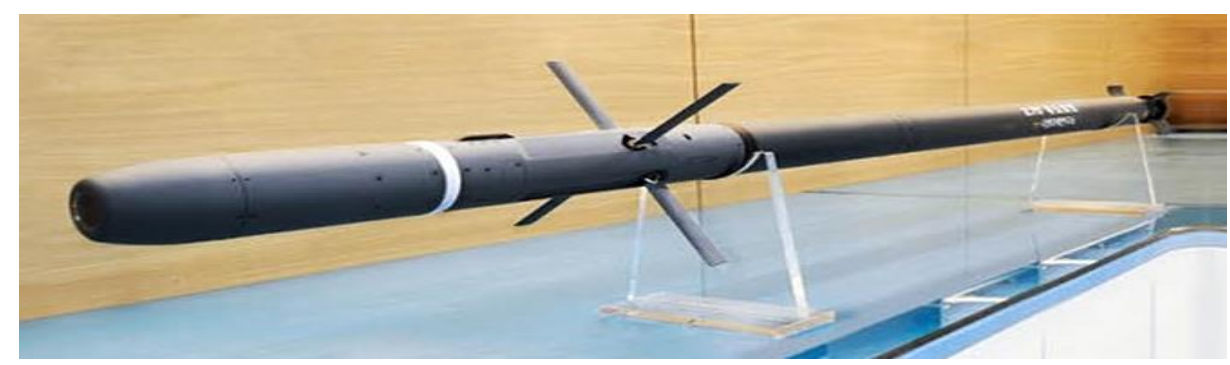

Рисунок 2 - Ракета С-8Кор

Разом з цим розглянуті способи комплектування боєприпасів СК потребують значних витрат для їх розроблення та виготовлення, тому перш за все слід розглядати варіанти конструктивних рішень, які потребують найменших витрат. Найменш витратним буде спосіб, який дозволить використовувати існуючі НРС. Варіантом

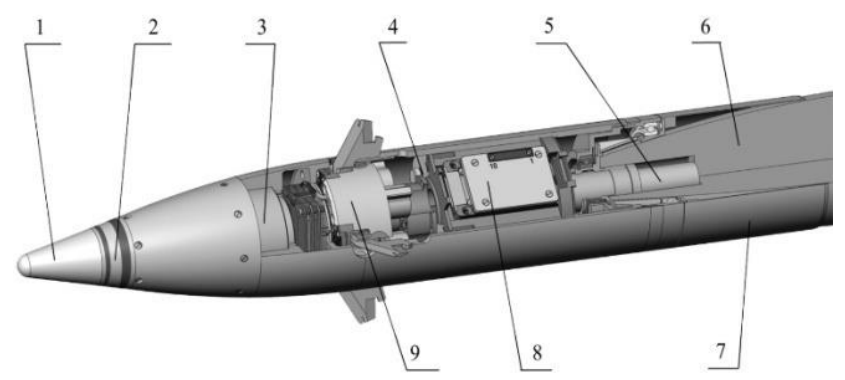

Рисунок 3 - Автономний блок керування:

1 - апаратура супутникової навігації, 2 - апаратура прийому польотного завдання,

3 - блок інерціальних датчиків, 4 - батарея живлення, 5 - підривник,

6 - штатний снаряд, 7 - аеродинамічна юбка, 8 - обчислювач, 9 - блок рульових приводів

Керування польотом штатного PC пасивній ділянці траєкторії за сигналами СНС за здійснюється аеродинамічними рулями АБК на 
навігаційної системи. Координати цілі з'єднувальних конструкцій на основі систем передаються до АБК перед пуском. АБК підшипників. Недоліком таких систем $\epsilon$ з'єднується з РС за допомогою підшипникового негативний влив сили тертя на забезпечення механізму. За рахунок АБК забезпечується стабілізованого положення СК під час точність стрільби з СКВ в межах 10 м. Менша обертання ракети (снаряда), що в свою чергу точність стрільби, порівняно з американськими впливає на точність визначення його ракетами "Zuni", буде компенсуватися вражаючою дією більш потужного заряду. АБК встановлюються на штатні 122-мм РС типу М210Ф, 9M538, 9M521 безпосередньо на ВП на місце встановлення штатного підривника [9].

У розглянутих прикладах комплектування ВТБ використовуються різні системи для подолання гіроскопічних ефектів, принцип роботи яких оснований на з'єднанні СК (блоку СК) з корпусом ракети або РС за допомогою положення під час польоту.

Для подолання залежності від гіроскопічних ефектів, що перешкоджають спробам зміни напрямку вектору швидкості РС, пропонується до конструкції СК замість електромеханічних (роторних) гіроскопів включити волоконні оптичні гіроскопи (ВОГ) [10].

Зовнішній вигляд ВОГ і компонування оптичних елементів у його корпусі наведено на рис. 4, принципову схему - на рис. 5.

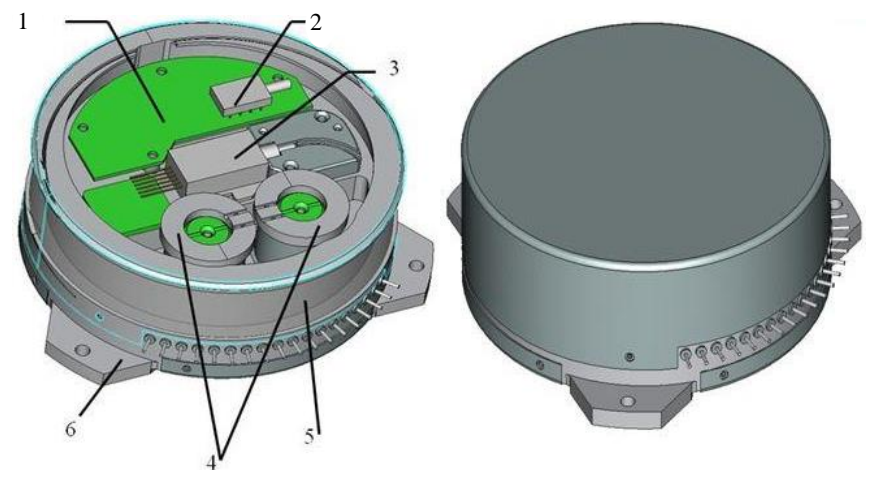

Рисунок 4 - Компонування оптичних елементів у корпусі ВОГ:

1 - плата підсилювача фотоструму, 2 - фотодіод, 3 - суперлюмінесцентний діод, 4 - фазові модулятори, 5 - котушка волоконного контуру, 6 - корпус

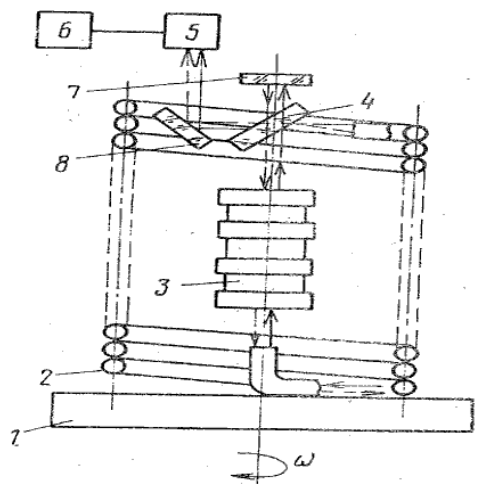

Рисунок 5 - Схема ВОГ:

1 - основа, 2 - багатошарова котушка з оптико-волоконним світловодом,

3 - джерело лазерного випромінювання, 4 - світлорозділювач,

5 - фотоприймач, 6 - лічильник інтерференційних смуг, 7,8 - дзеркала

вОГ у багатьох випадках може повністю замінити складні і дорогі електромеханічні (роторні) гіроскопи і тривісні гіростабілізаційні платформи.
Для вирішення завдань навігації рухливих об'єктів у військовій сфері найчастіше використовуються два типи гіроскопічних систем: лазерні та волоконно-оптичні [11]. Ці 
гіроскопічні системи відносяться до оптичних гіроскопічних систем, до фізичної основи яких закладено реалізований у кільцевій структурі ефект Саньяка $[12,14]$.

За оцінками багатьох фахівців, вОГ будуть значно дешевшими, більш надійнішими i простішими в експлуатації, у декілька разів меншими за габаритами та вагою ніж існуючі механічні та лазерні гіроскопи однакової точності, тому в майбутньому переважна більшість всіх гіроскопів, що застосовуються в системах навігації, керування і стабілізації об'єктів різного призначення, буде замінена волоконними оптичними гіроскопами.

Конструювання ВОГ на одномодових діелектричних світловодах визначає його особливі властивості:

потенційно високу чутливість (точність) приладу, яка на цей час на експериментальних макетах складає 0,1 град/год. і менше;

малі габарити і масу завдяки можливості створення ВОГ повністю на інтегральних оптичних схемах;

невисоку вартість виробництва i конструювання при масовому виготовленні і відносну простоту технології;

мале споживання енергії, що має важливе значення при використанні ВОГ на борту РС;

великий динамічний діапазон вимірюваних кутових швидкостей (наприклад, одним приладом можна вимірювати швидкість повороту від 1 град/год. до 300 град/с);

відсутність обертових механічних елементів (роторів) і підшипників, що підвищує надійність і здешевлює їх виробництво;

має практично миттєву готовність до роботи, оскільки не витрачається час на розкрутку ротора;

нечутливість до великих лінійних прискорень, отже і працездатність в умовах високих механічних перевантажень; високу стійкість перед перешкодами, низьку чутливість до потужних зовнішніх електромагнітних впливів завдяки діелектричній природі волокна;

слабку схильність проникаючої гамманейтронної радіації, особливо в діапазоні 1,3 мкм [13].

ВОГ може бути застосований в якості жорстко закріпленого на корпусі РС чутливого елемента (датчика) обертання в інерційних системах керування і стабілізації. Механічні гіроскопи мають так звані гіромеханічні помилки, які значно проявляються при маневруванні носія (ракети, снаряда). Ці помилки ще більш значні, якщо інерціальна система керування конструюється з жорстко закріпленими або "підвішеними" датчиками безпосередньо до корпусу носія. Перспектива використання оптичного датчика обертання, який має невелику вартість та здатний працювати без гіромеханічних помилок в інерціальній системі управління, $€$ досить вагомою причиною для проведення подальших досліджень у цьому напрямку.

Таким чином, властивості ВОГ, що дозволяють розробляти прості високоточні конструкції повністю на недорогих твердих інтегральних оптичних схемах за умов масового виробництва, визначають перспективність цього напрямку для подальшого удосконалення систем керування РСЗВ середнього калібру.

Враховуючи відомі технічні характеристики сучасних ВОГ, можна стверджувати, що включення їх до конструкції інерціальної навігаційної системи надасть можливість покращити точність їі роботи, зменшити габарити блоку керування ВТБ і за рахунок цього збільшити вагу та потужність бойової частини, а також зменшити вартість цих боєприпасів в цілому.

\section{Висновки}

1. Особливості ведення сучасних бойових дій показали необхідність застосування більшої кількості засобів ураження, що мають ознаки високоточної зброї.

2. Розглянуті приклади конструктивних рішень комплектування некерованих боєпри- пасів системами керування підтверджують можливість розроблення на їх основі вітчизняних ВТБ для РСЗВ середнього калібру.

3. Запропонований спосіб удосконалення конструкції системи керування ВТБ на основі застосування волоконних оптичних гіроскопів 
сприятиме розробленню нових технічних рішень іздешевленню ВТБ для РСЗВ.

\section{Список використаних джерел}

1. Дудка В. Д., Чуков А. Н., Шмараков А. Н. Высокоточные боеприпасы различного целевого назначения. Тула: Издательство ТулГУ, 2002. 292 c.

2. Макаровец Н. А., Устинов Л. А., Авотынь Б. А. Реактивные системы залпового огня и их эффективность. Тула: Издательство ТулГУ, 2005. 293 C.

3. Агафонов Ю. М., Грічанюк О. М., Журавльов О. О., Ткаченко Ю. А. Шляхи підвищення точності пусків реактивних снарядів комплексів повітряного та наземного базування. Системи озброєння і військова технікаю. 2015. № 4 (44). С. 3-6.

4. Обозов Л. Проблемы увеличения дальности стрельбы реактивной артиллерии. Военный парад, 2002. № 3 (51). C. 50-53.

5. Высокоточное оружие зарубежных стран. Т. 2. Танковые, артиллерийские, минометные КУВ, самоприцеливающиеся и самонаводящиеся боевые элементы: обзор аналит. Справ. / Лихтеров В.М. и др. / Тула: Издательство «Власта», 2011. С. 98134.

6. Дальнобойный

высокоточный управляемый артиллерийский снаряд большого калибра с аппаратурой спутниковой радионавигации / Коротков О. В., Благов С. Г., Огнев В. А., Долгов В. В. Известия РАРАН, 2016. №1 (91) С. 60-66.

7. Крупников А. Радиолокационные станции контрбатарейной борьбы основных зарубежных стран. Зарубежное военное обозрение, 2010. № 12. С. 32-41.

8. Управляемая ракета Laser-Guided Zuni Rocket (СШA). URL: https://en.topwar.ru/ 63960-upravlyaemaya-raketa-laser-guidedzuni-rocket-ha.html (дата звернення: 10.09.2020).

9. Автономные отсеки управления с аппаратурой спутниковой навигации для 122-мм реактивных снарядов. URL: http://btvtinfo.blogspot.com/2018/06/122. html (дата звернення: 10.09.2020).

10. Волоконно-оптический гироскоп. URL: https://patents.su/3-1714515-volokonnoopticheskiji-giroskop.html (дата звернення: 10.09.2020).

11. INS/GPS Technology Trends by George T. Schmidt / Advances in Navigation Sensors and Inte-gration Technology. RTO Lecture Series 232 (2004) Pre-Print. SET-064. p.1-7.

12. Лукьянов Д.П. Лазерные $и$ волоконнооптические гироскопы: состояние и тенденции развития. Гироскопия $и$ навигация, 1998. № 4 (23). С. 23-45.

13. Волоконный оптический гироскоп URL: https://works.doklad.ru/view/ILLBzY68ERo/ all.html (дата звернення: 10.09.2020).

14. Шереметьев А.Г. Волоконный оптический гироскоп. Москва: издательство «Радио и связь», 1987. 152 с.

\section{Анализ возможных способов повышения точности реактивных снарядов среднего калибра путем комплектования их системой управления}

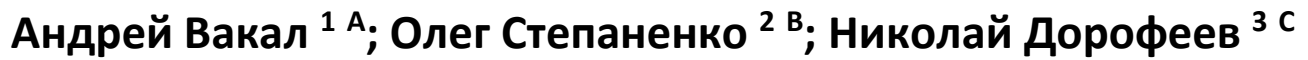

${ }^{1}$ Corresponding author: к.т.н., с.н.с., доцент кафедры, e-mail: vakal240870@gmail.com, ORCID: 0000-0001-7568-7686 ${ }^{2}$ Старший научный сотрудник научно-исследовательского отдела, e-mail: vip.oleg200673@ukr.net, ORCID: 0000-0002-8044-2292 ${ }^{3}$ Научный сотрудник научно-исследовательского отдела, e-mail: dorofeev83@meta.ua, ORCID: 0000-0001-8607-2483

А Сумской государственный университет, ул. Римского-Корсакова, 2, г. Сумы, 40000, Украина

в Научно-исследовательский центр ракетных войск и артиллерии, ул. Герасима Кондратьева, 165, г. Сумы, 40021, Украина с Центральный научно-исследовательский институт вооружения и военной техники ВС Украины, пр-кт Воздухофлотский, 28, г. Киев, 03049, Украина
} 


\title{
Аннотация
}

В статье проведен анализ известных конструктивных решений, используемых для комплектования неуправляемых авиационных ракет и неуправляемых реактивных снарядов системами управления с целью повышения их точности. Рассматриваются возможные способы комплектования реактивных боеприпасов к РСЗО среднего калибра системой управления и предлагается конструктивное решение по ее усовершенствованию.

Продолжение эскалации вооруженного конфликта на востоке Украины требует от руководства нашего государства и Вооруженных Сил Украины постоянно определять дальнейшие приоритетные направления повышения боеспособности воинских частей (подразделений) Вооруженных Сил Украины. Реактивные системы залпового огня (РСЗО) среднего калибра неоднократно доказывали свою эффективность при ведении боевых действий в различных вооруженных конфликтах по всему миру и продолжают оставаться одним из основных огневых средств, применяется в зоне проведения ООС. В условиях гибридной войны подразделения, вооруженные РСЗО среднего калибра, при поражении целей, расположенных в населенных пунктах, не могут компенсировать недостаточную точность стрельбы увеличением количества потраченных боеприпасов. Эффективного выполнения огневых задач в указанных условиях возможно достичь за счет существенного повышения точности боеприпасов к РСЗО среднего калибра.

Анализ положительного опыта ведущих в военном отношении стран мира в создании высокоточных боеприпасов (ВТБ) может быть использован при дальнейшей разработки ВТБ для РСЗО среднего калибра. Применение ВТБ совместно с модернизированными РСЗО среднего калибра обеспечит минимальное время подготовки к ведению огня и существенно сократит время их пребывания на огневой позиции, а значит повысит их живучесть и сделает контрбатарейную борьбу противника менее эффективной.

Ключевые слова: высокоточные боеприпасы, реактивная система залпового огня, система управления, автономный блок управления, волоконный оптический гироскоп.

\section{Analysis of possible methods of increasing the accuracy of medium-caliber rockets by equipping their control systems}

\author{
Andriy Vakal ${ }^{1}$ A; Oleg Stepanenko ${ }^{2}$ B; Mykola Dorofeev 3 C \\ ${ }^{1}$ Corresponding author: Candidate technical science., Associate Professor, e-mail: vakal240870@gmail.com, ORCID: 0000-0001-7568-7686 \\ ${ }^{2}$ Senior Research Fellow, e-mail: vip.oleg200673@ukr.net, ORCID: 0000-0002-8044-2292 \\ ${ }^{3}$ Researcher of the research department, e-mail: dorofeev83@meta.ua, ORCID: 0000-0001-8607-2483 \\ A Sumy State University, 2, Rimsky-Korsakov str., Sumy, 40000, Ukraine \\ ${ }^{B}$ Research Center for Missile Forces and Artillery, 165, Gerasim Kondratiev str., Sumy, 40021, Ukraine \\ ${ }^{\mathrm{C}}$ Central Research Institute of Armaments and Military Equipment of the Armed Forces of Ukraine, 28, Vozduhoflotsky, ave, Kyiv, 03049, Ukraine
}

\begin{abstract}
The article analyzes the known design solutions used to equip unguided aircraft missiles and unguided rockets with control systems in order to improve their accuracy. Possible ways of manning jet ammunition for medium-caliber MLRS with a control system are considered and a constructive solution for its improvement is proposed.

The continuation of the escalation of the armed conflict in the east of Ukraine requires the leadership of our state and the Armed Forces of Ukraine to constantly determine further priority areas for increasing the combat capability of military units (subdivisions) of the Armed Forces of Ukraine. Medium-caliber multiple launch rocket systems (MLRS) have repeatedly proved their effectiveness in the conduct of hostilities in various armed conflicts around the world and continue to be one of the main weapons used in the JFO zone. In a hybrid war, subunits armed with medium-caliber MLRS, when targets located in populated areas are hit, cannot compensate for the lack of firing accuracy by increasing the amount of ammunition spent. Effective execution
\end{abstract}


of fire missions under these conditions can be achieved by significantly increasing the accuracy of medium-caliber MLRS ammunition.

Analysis of the positive experience of the militarily leading countries of the world in the creation of high-precision ammunition (HPA) can be used in the further development of HPA for mediumcaliber MLRS. The use of HPA in conjunction with modernized medium-caliber MLRS will ensure the minimum preparation time for firing and significantly reduce the time they spend in a firing position, which means they will increase their survivability and make the enemy's counterbattery fight less effective.

Keywords: precision ammunition, multiple launch rocket system, control system, autonomous control unit, fiber optic gyroscope.

\section{References}

1. Dudka V. D., Chukov A. N., Shmarakov A. N. Vysokotochnye boeprypasy razlychnoho tselevoho naznachenyya. Tula: Yzdatel'stvo TulHU, 2002. $292 \mathrm{~s}$.

2. Makarovets N. A., Ustynov L. A., Avotyn' B. A. Reaktyvnye systemy zalpovoho ohnya y ykh éffektyvnost'. Tula: Yzdatel'stvo TulHU, 2005. $293 \mathrm{~s}$.

3. Ahafonov YU. M., Hrichanyuk O. M., Zhuravl'ov O.O., Tkachenko YU.A. Shlyakhy pidvyshchennya tochnosti puskiv reaktyvnykh snaryadiv kompleksiv povitryanoho ta nazemnoho bazuvannya. Kharkiv: KHNUPS: Systemy ozbroyennya i viys'kova tekhnikayu. 2015. № 4 (44). S. 3-6.

4. Obozov L. Problemy uvelychenyya dal'nosty strel'by reaktyvnoy artylleryy. Voennyy parad, 2002. № 3 (51). S. 50-53.

5. Vysokotochnoe oruzhye zarubezhnykh stran. T. 2. Tankovye, artylleryyskye, mynometnye KUV, samoprytselyvayushchyesya y samonavodyashchyesya boevye élementy: obzor analyt. Sprav. / Lykhterov V.M. y dr. / Tula: Yzdatel'stvo "Vlasta», 2011. C. 98-134.

6. Dal'noboynyy vysokotochnyy upravlyaemyy artylleryyskyy snaryad bol'shoho kalybra s apparaturoy sputnykovoy radyonavyhatsyy / Korotkov O.V., Blahov S.H., Ohnev V.A., Dolhov V.V. Yzvestyya RARAN, 2016. №1 (91) S. 60-66.

7. Krupnykov A. Radyolokatsyonnye stantsyy kontrbatareynoy bor'by osnovnykh zarubezhnykh stran. Zarubezhnoe voennoe obozrenye: zhurnal, 2010. № 12. S. 32-41.

8. Upravlyaemaya raketa Laser-Guided Zuni Rocket (SSHA). Available from : https://en.topwar.ru/63960-upravlyaemayaraketa-laser-guided-zuni-rocket-ha.html (data zvernennya: 10.09.2020).

9. Avtonomnye ot.seky upravlenyya s apparaturoy sputnykovoy navyhatsyy dlya 122-mm reaktyvnykh snaryadov. Available from: http://btvtinfo.blogspot.com/2018/ 06/122.html (data zvernennya: 10.09.2020).

10. Volokonno-optycheskyy hyroskop. Available from: https://patents.su/3-1714515volokonno-opticheskijj-giroskop.html (data zvernennya: 10.09.2020).

11. INS/GPS Technology Trends by George T. Schmidt / Advances in Navigation Sensors and Inte-gration Technology. RTO Lecture Series 232 (2004) Pre-Print. SET-064. p.1-7.

12. Luk'yanov D.P. Lazernye y volokonnooptycheskye hyroskopy: sostoyanye y tendentsyy razvytyya // Hyroskopyya y navyhatsyya, 1998. № 4 (23). S. 23-45.

13. Volokonnyy optycheskyy hyroskop. Available from: https://works.doklad.ru /view/ILLBzY68ERo/all.html (data zvernennya: 10.09.2020).

14. Sheremet'ev A.H. Volokonnyy optycheskyy hyroskop. Moskva: yzdatel'stvo «Radyo y svyaz'», 1987. $152 \mathrm{~s}$. 